\title{
INFLUÊNCIA DA COLORAÇÃO DAS SEMENTES NA GERMINAÇÃO DE PHYLLANTHUS TENELLUS ROXB. E PHYLLANTHUS NIRURI L. (EUPHORBIACEAE)
}

\author{
Silvia Venturi' \\ Áurea Maria Randi ${ }^{1}$
}

Recebido em 21/11/96. Aceito em 31/07/97

\begin{abstract}
RESUMO - (Influência da coloração das sementes na germinação de Phyllanthus tenellus Roxb. e Phyllanthus niruri L.). Heteromorfia foi observada em sementes de Phyllanthus tenellus Roxb. e $P$. niruri L. Há dois tipos de sementes: marrons e amarelas. As quantidades desses tipos de sementes variaram ao longo do ano nas coletas realizadas. As sementes marrons apresentam maior massa e porcentagem de germinação mais alta. Proteínas e açúcares solúveis totais foram analisados em sementes de $P$. niruri sendo que teores mais elevados dessas substâncias de reserva foram verificados em sementes coletadas no final da primavera, enquanto teores menores foram encontrados em sementes coletadas no outono, embora não tenha sido verificada alteração na massa dessas sementes cuja germinação foi menor do que na coleta de primavera. Os teores de açúcares solúveis totais foram maiores em sementes amarelas de $P$. niruri e em sementes marrons de $P$. tenellus. A maior porcentagem de germinação ocorreu em sementes marrons de ambas as espécies, sob luz branca contínua. Após 10 meses de armazenamento em câmara fria a $\pm 4^{\circ} \mathrm{C}$, a germinação de sementes marrons de $P$. tenellus foi reduzida em aproximadamente $50 \%$.
\end{abstract}

Palavras-chave: Phyllanthus tenellus, Phyllanthus niruri, heteromorfia, germinação

\begin{abstract}
The influence of seed color on the germination of Phyllanthus tenellus Roxb. and Phyllanthus niruri L.). Heteromorphy was observed in Phyllanthus tenellus and $P$. niruri seeds. There are two kinds of seeds: brown and yellow. There is variation in the number of the two kinds of seeds harvested in different periods of the year. Brown seeds present higher mass and higher percentage of germination. Proteins and soluble sugars were also analysed in $P$. niruri seeds and the highest level of these storage substances was found in seeds harvested in late spring. In $P$. niruri the level of protein and soluble sugars was smaller in the sample harvested in autumn, but no alteration was seen in seed mass. Seed germination of the autumn collection was smaller than the spring collection. Soluble sugars level was higher in yellow seeds of $P$. niruri and in brown seeds of $P$. tenellus. Brown seeds germination was higher under continuous white light. After 10 months of storage at $\pm 4^{\circ} \mathrm{C}$ the germinability of the $P$. tenellus brown seeds decreased about $50 \%$.
\end{abstract}

Key words: Phyllanthus tenellus, Phyllanthus niruri, heteromorphy, germination

\footnotetext{
' Universidade Federal de Santa Catarina, Departamento de Botânica, C.P. 476, CEP 88040-900, Florianópolis, SC, Brasil
} 


\section{Introdução}

O gênero Phyllanthus é um dos maiores da família Euphorbiaceae, contendo mais de 700 espécies (Unander et al. 1990). Diversas plantas desse gênero, conhecidas popularmente como quebra-pedra, têm sido usadas na medicina popular brasileira e em diversos países no tratamento de algumas enfermidades, por exemplo: edema, excesso de albumina e ácido úrico, calcificação na bexiga, fígado e rins (Unander et al. 1991).

Com relação ao crescimento, plantas de Phyllanthus amarus, $P$. caroliniensis, $P$. urinaria, $P$. debilis e $P$. niruri foram cultivadas com o intuito de fazer uma avaliação na atividade da inibição in vitro da DNA polimerase viral e também de desenvolver sistemas para a produção de plantas de alta qualidade visando as extrações em grande escala (Unander et al. 1991; Unander et al. 1993). Com relação à germinação, as primeiras sementes de $P$. amarus liberadas após deiscência das cápsulas são verde-escuras e apresentam as maiores porcentagens de germinação. Com o passar do tempo, aumenta a porcentagem de sementes verde-claras, cuja porcentagem de germinação é mais baixa (Unander et al. 1995 ).

A heteromorfia em sementes e frutos já foi observada em espécies de várias famílias. É uma característica comum em Compositae, Cruciferae e Chenopodiaceae (Beneke et al. 1993; Bewley \& Black 1994). Heteromorfia em frutos e sementes foi observada em Ceratocapnos heterocarpa Durieu, espécie da família Fumariaceae (De Clavijo 1994).

Apesar da potencialidade do uso de plantas do gênero Phyllanthus e do fato de que chás e cápsulas dessas plantas já estejam sendo comercializados no Brasil por laboratórios de fitoterápicos, pouco se conhece a respeito dos hábitos de reprodução e do crescimento dessas plantas. Sabe-se também, por meio de informações diretas dos fabricantes, que sua obtenção é feita por meio do extrativismo, não havendo qualquer controle da qualidade das plantas e mesmo da identificação precisa das espécies.

Os principais objetivos deste trabalho foram relacionar cor da semente com porcentagem de germinação e determinar o comportamento das espécies quanto ao fotoblastismo.

\section{Material e métodos}

Frutos de Phyllanthus tenellus Roxb. e de P. niruri L. foram coletados no Campus da Universidade Federal de Santa Catarina, Florianópolis, Brasil. As exsicatas do material estudado estão depositadas no herbário do Departamento de Botânica da Universidade Federal de Santa Catarina sob números 224 FLOR 23088 e 226 FLOR 23079 e foram coletadas por Miriam Ulysséa. Plantas foram coletadas aleatoriamente, sendo retirados todos os frutos totalmente desenvolvidos de cada uma. Estes secaram ao ambiente, o que provocou sua deiscência e liberação de sementes. Teste de viabilidade foi realizado em sementes que foram mantidas em frascos de vidro fechados, em câmara fria $\mathrm{a} \pm 4^{\circ} \mathrm{C}$ durante 10 meses. A deiscência só ocorre em frutos 
maduros. Amostras de sementes foram separadas por coloração, obtendo-se dois grupos nítidos: sementes marrons e sementes amarelas, cujas porcentagens de germinação foram também analisadas.

Para os testes de germinação, as sementes foram previamente mergulhadas por uma hora em solução $0,1 \%$ de Captan e semeadas em placas de Petri de $9 \mathrm{~cm}$ de diâmetro, previamente autoclavadas e revestidas com papel de filtro umedecido. Foram utilizadas quatro repetições inteiramente casualizadas de 50 sementes cada. As placas foram colocadas dentro de sacos de polietileno preto, para o tratamento de escuro, sendo que nesse caso a germinação foi avaliada sob luz verde de segurança. Foram realizadas contagens semanais do número de sementes germinadas por placa de Petri. Na maioria das coletas, a porcentagem de germinação ficou estabilizada após 42 dias, quando foi realizada a avaliação final das sementes germinadas. Os experimentos de germinação foram conduzidos em câmaras de germinação a $25^{\circ} \mathrm{C}$, iluminadas por duas lâmpadas fluorescentes PHILLIPS-FLD-C15/54 fixadas na parede posterior. A intensidade luminosa média na altura das placas foi de $1500 \mathrm{Wcm}^{-2}$. As sementes foram consideradas germinadas a partir da protrusão radicular. Sementes marrons e amarelas (100 de cada) foram clarificadas pelo método de Herr (1971), que consiste na passagem rápida das mesmas em bateria de concentração crescente de álcool, diferenciação em xilol durante cinco minutos e embebição em líquido diafanizador durante quatro horas. O líquido diafanizador foi preparado com hidrato de cloral, ácido fênico, óleo de cravo, ácido láctico e xilol na proporção de 2:2:2:2:1 (v/v). O material diafanizado foi então observado sob microscópio estereoscópico.

Açúcares solúveis presentes nas sementes foram extraídos em MCW (metanol, clorofórmio e água 12:5:3 v/v) de acordo com Shannon (1968) e quantificados pelo reagente de antrona segundo Umbreit \& Burris (1964). Três amostras de 200 sementes foram previamente pesadas antes das extrações. As dosagens de açúcares solúveis totais foram obtidas a partir de uma curva padrão de glicose, cujos coeficientes de correlação r e regressão linear b foram calculados. Proteínas solúveis foram extraídas em $\mathrm{NaOH}(0,1 \mathrm{~N})$ e quantificadas pelo método de Bradford (1976). A extração de proteínas foi realizada apenas em Phyllanthus niruri em função da maior disponibilidade de sementes. A análise de variância foi feita para comparar três ou mais tratamentos. Nos casos em que houve diferença significativa entre os tratamentos, foi calculada a Diferença Mínima Significativa $\left(\mathrm{DMS}_{5 \%}\right.$ ) pelo teste de Tukey, conforme Snedecor \& Cochran (1967). Quando se compararam dois tratamentos procedeu-se ao teste t, de Student (Snedecor \& Cochran 1967).

\section{Resultados e discussão}

Plantas de Phyllanthus tenellus e P. niruri apresentam dois tipos de sementes: marrons e amarelas. As porcentagens de sementes marrons e amarelas de $P$. tenellus foram bastante variáveis entre as diferentes coletas, o mesmo ocorrendo para as porcentagens de germinação sendo que as sementes amarelas sempre apresentaram menores porcentagens de germinação, do que as sementes marrons (Tab. 1), o mesmo ocorrendo em P. niruri, cujas sementes amarelas não germinam e as porcentagens de 
germinação de sementes marrons também foram variáveis (Tab. 2). Plantas de $P$. niruri cultivadas na primavera e no outono floresceram e frutificaram no verão e no inverno seguintes, respectivamente (Venturi \& Randi 1997), confirmando os dados obtidos para a disponibilidade de sementes desta espécie ao longo do ano. A heteromorfia observada em sementes das duas espécies de Phyllanthus caracteriza-se pela diferença na coloração, na massa e na germinabilidade de sementes. Há poucos dados na literatura sobre a germinação de sementes do gênero Phyllanthus. Heteromorfia foi verificada também em sementes de $P$. amarus, sendo que as sementes liberadas das primeiras cápsulas a sofrerem deiscência apresentam maiores porcentagens de germinação sendo verde-escuras, ao passo que as sementes liberadas posteriormente são verde-claras e germinam em menor porcentagem e mais vagarosamente (Unander et al. 1995). Exemplos de he-teromorfia em frutos e sementes já foram encontrados em espécies de diversas famílias contribuindo para a porcentagem de germinação característica de cada espécie. Stevia rebaudiana L., uma Compositae, produz três tipos de aquênios: marrom-escuros férteis, e marrom-escuros e amarelos ambos estéreis (Felippe \& Lucas 1971; Randi \& Felippe 1980). Espécies da família Vochysiaceae, como Qualea grandiflora Mart. e Qualea cordata Spreng. apresentam sementes marromescuras ou marrom-claras, sendo que somente as do segundo tipo são viáveis (Felippe 1990; Godoy \& Felippe 1992)

Tabela 1. Ocorrência de sementes amarelas e marrons de $P$. tenellus em diferentes coletas e germinação sob luz branca constante a $25^{\circ} \mathrm{C}$, após 42 dias. Letras diferentes indicam diferenças estatisticamente significativas entre os dois tipos de sementes pelo teste " $t$ " a $95 \%$ de probabilidade. Traços indicam que os dados não foram determinados.

\begin{tabular}{lcccc}
\hline Data da coleta & $\begin{array}{c}\text { sementes } \\
\text { amarelas (\%) }\end{array}$ & $\begin{array}{c}\text { germinação de } \\
\text { sementes amarelas (\%) }\end{array}$ & $\begin{array}{c}\text { sementes } \\
\text { marrons (\%) }\end{array}$ & $\begin{array}{c}\text { germinação de } \\
\text { sementes marrons (\%) }\end{array}$ \\
\hline março/90 & 59,6 & - & 40,4 & - \\
abril/90 & 37,7 & - & 62,3 & - \\
junho/90 & 15,3 & $34,0 \mathrm{a}$ & 84,7 & $90,0 \mathrm{~b}$ \\
novembro/91 & 30,7 & $46,0 \mathrm{a}$ & 69,3 & $65,0 \mathrm{~b}$ \\
junho/92 & - & $5,5 \mathrm{a}$ & - & $52,0 \mathrm{~b}$ \\
abril/93 & 10,7 & $20,0 \mathrm{a}$ & 89,3 & $70,0 \mathrm{~b}$ \\
\hline
\end{tabular}

Tabela 2. Ocorrência de sementes amarelas e marrons de Phyllanthus niruri em diferentes coletas e germinação de sementes marrons sob luz branca constante a $25^{\circ} \mathrm{C}$, após 42 dias. Traços indicam que os dados não foram determinados.

\begin{tabular}{lccc}
\hline Data de coleta & sementes marrons $(\%)$ & sementes amarelas $(\%)$ & $\begin{array}{c}\text { germinação de sementes } \\
\text { marrons }(\%)\end{array}$ \\
\hline setembro/91 & 82,8 & 17,2 & 34,0 \\
fevereiro/92 & 73,4 & 26,6 & 21,2 \\
junho/92 & 58,0 & 41,0 & 18,0 \\
dezembro/92 & 65,8 & 34,2 & 62,0 \\
abril/94 & - & - & 38,0 \\
\hline
\end{tabular}


O efeito da luz e do escuro na germinação foi verificado em sementes marrons de Phyllanthus tenellus coletadas em abril de 1993. A porcentagem de germinação de sementes marrons foi de aproximadamente $70 \%$ em luz branca constante, mas não houve germinação no escuro. A germinação de sementes marrons de $P$. niruri coletadas em setembro de 1991, na luz contínua (34\%) foi significativamente maior do que no escuro contínuo (1\%). Comportamento fotoblástico semelhante foi observado também em $P$. amarus cujas sementes igualmente requerem luz para germinar (Unander et al. 1995).

A dissecção de sementes marrons e amarelas clarificadas de Phyllanthus tenellus e de $P$. niruri mostrou a presença de embriões nos dois tipos, mas as sementes marrons apresentaram-se completamente preenchidas com reservas, enquanto que as sementes amarelas apresentaram espaços vazios entre o endosperma e a testa. Em alguns casos, sementes que apresentam heteromorfia podem ter como característica a ausência de embrião, como é o caso de sementes marrons de Qualea cordata (Godoy \& Felippe 1992).

A Tab. 3 mostra que as sementes marrons de Phyllanthus tenellus apresentam maior massa que as amarelas e que o conteúdo de açúcares solúveis totais foi maior em sementes marrons. A Tab. 4 mostra que as sementes marrons de $P$. niruri apresentam maior massa do que as sementes amarelas.

Tabela 3. Massa fresca total de três amostras de 200 sementes de Phyllanthus tenellus e conteúdo de açúcares solúveis totais de sementes marrons e amarelas. Letras diferentes indicam diferenças entre colunas, pelo teste "t" a $95 \%$ de probabilidade. MF significa massa fresca.

\begin{tabular}{lcc}
\hline & Sementes marrons & Sementes amarelas \\
\hline Massa (mg) & $111,00 \mathrm{a}$ & $81,00 \mathrm{~b}$ \\
mg. açúcar solúvel. mg MF & $29,09 \mathrm{a}$ & $18,27 \mathrm{~b}$ \\
\hline
\end{tabular}

Tabela 4. Massas frescas e conteúdos de açúcares solúveis totais e proteínas em sementes marrons e sementes amarelas de Phyllanthus niruri coletadas em duas épocas diferentes (Massa fresca total de três amostras de 200 sementes). Letras minúsculas indicam diferenças entre os dois tipos de sementes e letras maiúsculas indicam diferenças entre as coletas pelo teste " $\mathrm{t}$ " de Student a 95\% de probabilidade. MF significa massa fresca.

\begin{tabular}{lcr}
\hline & Data da coleta & \\
\hline Massa de sementes marrons $(\mathrm{mg})$ & dezembro/92 & abril/94 \\
Massa de sementes amarelas $(\mathrm{mg})$ & $221,14 \mathrm{aA}$ & $207,00 \mathrm{aA}$ \\
mg açúcares. $\mathrm{mg} \mathrm{MF}^{-1}$ de sementes marrons & $120,16 \mathrm{bA}$ & $113,40 \mathrm{bA}$ \\
mg açúcares. $\mathrm{mg} \mathrm{MF}^{-1}$ de sementes amarelas & $35,11 \mathrm{aA}$ & $15,10 \mathrm{aB}$ \\
mg proteínas. $\mathrm{mg} \mathrm{MF}^{-1}$ de sementes marrons & $44,60 \mathrm{bA}$ & $21,30 \mathrm{bB}$ \\
mg proteínas. $\mathrm{mg} \mathrm{MF}^{-1}$ de sementes amarelas & $87,51 \mathrm{aA}$ & $43,14 \mathrm{aB}$ \\
\hline
\end{tabular}

Teores de açúcares solúveis totais foram maiores em sementes amarelas, mas não houve diferença nos teores de proteínas entre os dois tipos de sementes. Entretanto, esses teores foram proporcionais à massa das sementes. As sementes marrons coletadas em dezembro de 1992 apresentaram maior conteúdo de proteínas totais e 
açúcares solúveis totais do que sementes coletadas em abril de 1994. Observou-se que as sementes marrons das duas coletas apresentaram massas semelhantes. É possível que a baixa germinação das sementes amarelas de $P$. tenellus e a ausência de germinação desse tipo de sementes em $P$. niruri devam-se às menores massas, visto que a dissecção mostrou espaços vazios entre a testa e o endosperma. Em $P$. niruri é possível que ocorra alguma influência de fatores ambientais durante o período de desenvolvimento das sementes pois nessa espécie observou-se que as sementes coletadas em abril de 1994 mostraram teores mais baixos das substâncias de reservas analisadas do que sementes coletadas em dezembro de 1992. As sementes marrons e amarelas coletadas em abril apresentaram massas semelhantes às de dezembro. Observou-se também que a coleta realizada em abril/94 apresentou porcentagens inferiores de sementes marrons enquanto que a coleta realizada em dezembro/92 mostrou porcentagens maiores de sementes marrons. Entretanto, seriam necessárias várias coletas realizadas em anos consecutivos para se confirmar se as variações ocorreram devido a fatores ambientais ou se foram completamente casuais. Já foi verificado para diver-sas espécies que sementes de maior tamanho ou de maior massa apresentam maior germinação, viabilidade e taxas de emergência (Hendrix 1984; Stanton 1984; Winn 1988). Por exemplo, as sementes de maior massa de Coreopsis lanceolata L. espécie herbácea perene pertencente à família Compositae, quando enterradas ao solo conseguem emergir de pequenas profundidades e possuem maior taxa de emergência que sementes de menores massas (Banovetz \& Scheiner 1994). A germinação de sementes de Miconia cinnamomifolia (DC) Naudin (Melastomataceae) é mais alta em sementes de maiores massas e tamanhos (Amaral \& Paulilo 1991/1992). Efeito semelhante foi observado em sementes de Aesculus indica Colebr., espécie pertencente à família Hippocastanasceae (Bhagat et al 1993). Entretanto, a massa da semente de Virola hoschnyi Warb. (Myristicaceae) não afetou a porcentagem de germinação (Gonzales 1993).

Um teste de armazenamento de sementes de Phyllanthus tenellus foi realizado com sementes coletadas em junho/92. Nessa coleta, a germinação de sementes marrons recém coletadas foi de $52 \%$ e após 10 meses de armazenamento a $\pm 4^{\circ} \mathrm{C}$, somente $18 \%$ das sementes germinaram, mostrando que houve redução de $65,38 \%$ na porcentagem de germinação de sementes marrons de $P$. tenellus e não houve germinação de sementes amarelas após esse período de armazenamento. Unander et al. (1995) observaram que o armazenamento de sementes de $P$. amarus a $10^{\circ} \mathrm{C}$ provocou uma drástica redução da germinação após um ano, enquanto que temperaturas de $20^{\circ} \mathrm{C}$ ou $-20^{\circ} \mathrm{C}$ mantiveram-nas viáveis por mais de um ano.

As sementes de Phyllanthus tenellus e $P$. niruri, além da heteromorfia, mostram também sensibilidade à luz e o tempo de viabilidade das sementes de $P$. tenellus armazenadas sob refrigeração parece ser relativamente curto.

\section{Agradecimentos}

À Beatriz Clair Andrade, pelo apoio técnico; à Prof.a Leila da Graça Amaral, do Departamento de Botânica da Universidade Federal de Santa Catarina e à Bióloga 
Miriam Ulysséa, pela identificação das plantas. Silvia Venturi agradece ao CNPq pela Bolsa de Iniciação Científica (Processo n 800097/91) e Áurea Maria Randi agradece ao $\mathrm{CNPq}$ pelo apoio financeiro (Processo $\mathrm{n}^{\circ} 404588 / 91$ ) e pela Bolsa de Pesquisa (Processo n 300372/89).

\section{Referências bibliográficas}

Amaral, L.I.V. \& Paulilo, M.T.S. 1991/1992. Efeito da luz, temperatura, reguladores de crescimento e nitrato de potássio na germinação de Miconia cinnamomifolia (DC) Naudin. Insula 21: 59-86.

Banovetz, S.J. \& Scheiner, S.M. 1994. The effects of seed mass on the seed ecology of Coreopsis lanceolata. The American Midland Naturalist 131: 65-74.

Bhagat, S.; Singh, O. \& Singh, V. 1993. Effect of seed weight on germination, survival and initial growth of horsechestnut (Aesculus indica Colebr. in the nursery. Indian Journal of Forestry 119: 627-629.

Beneke, K.; Rooyen, M.W.; Theron, G.K. \& Van De Venter, H.A. 1993. Fruit polymorphism in ephemeral species of Namaqualand: III. Germination differences between the polymorphic diaspores. Journal of Arid Environments 24: 333-344.

Bewley, J.D. \& Black, M. 1994. Seeds. Physiology of Development and Germination. $2^{\text {nd }}$ Edition. Plenum Press. New York and London.

Bradford, M.M. 1976. A rapid and sensitive method for the quantitation of micrograms quantities of protein utilizing the principle of protein-dye binding. Analytical Biochemistry 72: 248-254.

De Clavijo, E.R. 1994. Heterocarpy and seed polymorphism in Ceratocapnos heterocarpa (Fumariaceae). International Journal of Plant Science 155(2): 196-202.

Felippe, G.M. 1990. Qualea grandiflora: the seed and its germination. Revista Brasileira de Botânica 13(1): 33-37.

Felippe, G.M. \& Lucas, N.M.C. 1971. Estudo da viabilidade dos frutos de Stevia rebaudiana Bert. Hoehnea 1(1): 95-105.

Godoy, S.M. \& Felippe, G.M. 1992. Qualea cordata: a semente e sua germinação. Revista Brasileira de Botânica 15(1): 17-21.

Gonzales J.E. 1993. Effect of seed size on germination and seedling vigor of Virola koschnyi Warb. Forestry Ecology and Management 57: 275-281.

Hendrix, S.D.1984. Variation in seed weight and its effects on germination in Pastinaca sativa L.(Umbelliferae). American Journal of Botany 71(6): 795-802.

Herr Jr, J.M. 1971. A new clearing-squash technique for the study of ovule development in angiosperms. American Journal of Botany 58(8): 785-790.

Randi, A.M. \& Felippe, G.M. 1980. Detecção de esteviosídeo e susbstâncias giberelínicas no aquênios de Stevia rebaudiana: efeitos de esteviosídeo em germinação. Revista Brasileira de Botânica 3(1): 55-58.

Shannon, J.C. 1968. A procedure for the extraction and fractionation of carbohydrates from immature Zea mays kernels. Research Bulletin (Purdue) 842: 1-8.

Snedecor, G.H. \& Cochran, W.C. 1967. Statistical methods. The Iowa State University Press. Iowa.

Stanton, M.L. 1984. Developmental and genetic sources of seed weight variation in Raphanus raphanistrum L. (Brassicaceae). American Journal of Botany 71(8): 1090-1098.

Umbreit, W.W. \& Burris, R.H. 1964. Method for glucose determination and other sugars. Manometric techniques. $1^{\text {st }}$ Edition. Burgess Publishing Co.

Unander, D.W.; Webster, G.L. \& Blumberg, B.S. 1990. Records of usage or assays in Phyllanthus (Euphorbiaceae) I. Subgenera Isocladus, Kirganelia, Cicca and Emblica. Journal of Ethnopharmacology 30: 233-264.

Unander, D.W.; Webster, G.L. \& Blumberg, B.S. 1991. Uses and bioassays in Phyllanthus (Euphorbiaceae): a compilation II. The subgenus Phyllanthus. Journal of Ethnopharmacology 34: 97-133.

Unander, D.W.; Bryan, H. H.; Lance, C.J. \& Mcmillan Jr., R.T. 1993. Cultivation of Phyllanthus amarus 
and evaluation of variables potentially affecting yield and inhibition of viral DNA polymerase. Economic Botany 47(1): 79-88.

Unander, D.W.; Bryan, H. H.; Lance, C.J. \& McMillan JR, R.T. 1995. Factors affecting germination and stand establishment of Phyllanthus amarus (Euphorbiaceae). Economic Botany 49(1): 49-55.

Venturi, S. \& Randi, A.M. 1997. Preliminary studies on the growth of Phyllanthus niruri L.(Euphorbiaceae). Biotemas 10(1): 61-70.

Winn, A.A. 1988. Ecological and evolutionary consequences of seed size in Prunella vulgaris. Ecology 69: 1537-1544. 